Time being available towards the close of the hour, Mr Abbot reported briefly on new thermo-electric measures of the energy distribution in stellar spectra; Mr Merrill recommended caution in the use of the letter $s$ in describing spectra of the hotter stars (since, like $c$ and $n$, it is doubtful if it has a definite physical significance); and Mr Wildt reported on calculations which show that continuous absorption by negative atomic ions of hydrogen may have a significant part in producing opacity in the atmospheres of stars of the solar type.

The Commission then adjourned.

\title{
COMMISSION 30 (RADIAL VELOCITIES)
}

President: Dr W. S. Adams.

Secretary: Prof. B. J. BoK.

Six members of the Commission were present when the President opened the meeting. The first matter on the agenda was the consideration of the reports of the three sub-commissions. The members of the Commission were unanimous in their praise for the excellent work done by the members of these sub-commissions. It was decided unanimously that the three reports be accepted unchanged and that the sub-commissions be continued for another period of three years.

The report of the President of the Commission was accepted without changes. Special attention was called to the four recommendations at the end of the report. Harper and Adams emphasized the importance of the recommendation referring to the need for further observations for the brighter stars with uncertain radial velocities.

After the completion of the formal part of the meeting the members exchanged views on several specific problems. The President read a letter from Hagihara which mentioned that work on radial velocities would probably be undertaken in Japan after the completion of the 26-inch telescope at Tokyo. Freundlich and Mohr requested further observations of radial velocity for faint $B$ stars. They pointed out that, even in the northern hemisphere, a great deal of work remained to be done. It appeared that some of the stars to which Freundlich and Mohr referred were already on the programmes of Beals and Merrill. In a brief discussion on the K-effect Plaskett drew attention to a recent paper by himself in the M.N.R.A.S.

A discussion of the work on objective-prism radial velocities of the Harvard Observatory brought out the desirability of checks on the system of velocities by means of slit velocities of three to five stars in each field. The President pledged the co-operation of the members of the Commission.

Redman brought up the matter of the measurement of radial velocities for stars with hazy lines. It appeared that attempts to measure such velocities from microdensitometer tracings had not been very successful. Merrill mentioned that higher accuracy could probably be obtained through the use of Evershed's method of superposition of a positive and negative. 